but with the exception of the two patients who did show a little dizziness we could not show any significant postural drop in blood pressure in the series.

Prazocin was not continued in all of our patients since this was not part of the experimental design of this study. We have previously published longer-term studies on prazocin, one of which was a controlled double-blind crossover sıudy of 26 weeks' duration. I do not think one needs to try and defend not continuing the therapy in some cases where this was not part of the experimental design; in any case, it was related to some very mundane things such as tablet supply, transfer of patients to other clinics, and the like. The same answer could be given to the next question, which was, Why did only seven volunteer for rechallenge with a smaller dose of the drug ? The reason is that only seven were asked to do so; the other five were lost to follow-up through a variety of reasons, none of which was related to the previous prazocin therapy. Therefore the rather sinister assumptions made by $\mathrm{Dr}$ Bendall are completely unjustified and the suggestion that these patients must be regarded as "failures" in this study is beyond comprehension.

Dr Bendall suggests that the whole study is in any case ethically unacceptable. This must of necessity be a highly subjective judgment; I do not regard it as ethically unacceptable to rechallenge patients with a very much smaller single dose of potentially valuable antihypertensive agent, under careful observation in a hospital environment, in order to test the hypothesis that the side effects are dosedependent. Rechallenge is an accepted technique widely used in diagnostic and therapeutic as well as experimental situations. If we were to stop these studies, not only would it inhibit a large area of experimental therapeutics, but also many studies designed to determine the needs of individual patients could not be done. In any case, the study was completely consistent with the final paragraph of $\mathrm{Dr}$ Bendall's own short report in the $B M \mathcal{F}^{1}$ : "We conclude that the recommended starting dose of $2 \mathrm{mg}$ is too high and that further investigations are needed to establish a safe starting dose..."

I am happy to say that I can agree with one remark in Dr Bendall's letter. That is that the general acceptance of prazocin must await adequate clinical trials in which the $0.5-\mathrm{mg}$ starting dose is compared with other, established, antihypertensive agents.

Departments of Physiology and Medicine,

University of the Witwatersrand Medical School,

Johannesburg,

${ }^{1}$ Bendall, $\mathrm{M} \mathrm{J}$, Baloch, $\mathrm{K} \mathrm{H}$, and Wilson, $\mathrm{P} \mathrm{R}$, British Medical fournal, 1975, 2, 727.

\section{Chemotherapy in breast cancer}

SIR,-Your leading article on this subject (9 October, $p$ 832) does less than justice to the item on cancer treatment broadcast in the BBC Radio 4 "World Tonight" programme on 7 July. This programme, quite properly, included statements by Dr Frank Rauscher, Director of the National Cancer Institute in the USA, in which he made certain claims about the success being achieved in treating breast cancer by chemotherapy. Because the claims were so surprising the programme gave roughly equal time to a member of the British Breast Group, who gave the background to the claims and who stressed the caution with which they should be regarded. The programme was both accurate and balanced and did not transform the American claims "into a triumphant fanfare" as your article suggests.

JAMES WILKINSON Science correspondent,
British Broadcasting Corporation

London W1

***James Wilkinson misses the point. Cancer sufferers will always clutch at straws, and-as we know from the episode of the Issels clinic -if they hear of a new form of treatment they will want it. What has happened in the USA, and what we hope to avoid here, is clamour by patients for adjuvant chemotherapy before it has been evaluated. The presence of a cautionary spokesman to "balance" the enthusiasm of $\mathrm{Dr}$ Rauscher did little to diminish the impact of his claims on an uncritical audience.-ED, $B M F$.

\section{Compulsory seat belts}

SIR,-It is all too easy to fall into uncritical agreement with Dr T H S Burns (16 October, p 946) and to believe that wearing seat belts increases carelessness on the grounds that the consequences of careless driving are mitigated by the wearing of a seat belt.

Having myself always worn seat belts since the British Standard was published in the early 'sixties and talked to many people since, I am convinced that wearing a seat belt heightens awareness of the consequences of careless driving and leads to safer driving rather than the reverse.

London W1

M J W BARKER

\section{Neonatal electrocardiogram}

SIR,-How strange that Dr D P Southall and his colleagues (11 September, p 615) should state that their preliminary observations of the neonatal electrocardiogram have identified the need to define more clearly the range of normal variation without telling us what yardsticks they have found wanting.

HAMISH WATSON

Department of Cardiology,

Ninewells Teaching Hospital and

Medical School,

***We sent a copy of this letter to $\mathrm{Dr}$ Southall, whose reply is printed below.-ED, $B M F$.

SIR,-We indicated in our article (11 September, $p$ 615) that several workers had previously given yardsticks of normality for interpretation of the neonatal electrocardiogram. Since these studies are quoted in most textbooks of paediatric cardiology, including Dr Watson's own, ${ }^{1}$ we felt it would be tedious to list these textbooks as references.

The usually quoted source references for tables which appear in textbooks are those of Walsh ${ }^{2}$ and Leibman. ${ }^{3}$ The former had a relatively small number of patients, while the latter recategorised previously published data. We found that many of the values in normal neonates fell outside their criteria for normality, particularly in respect of voltages and axis. However, until more data are at hand we do not feel justified in producing new tables; we merely wish to alert cardiologists to the possible deficiencies of the present tables such as those published in Dr Watson's textbook.

D SOUTHALL Dorset County Hospital,
Dorchester, Dorset

Paediatric Cardiology, ed H Watson. London, LloydLuke, 1968.

2 Walsh, S Z, British Heart fournal, 1963, 25, 784.

Leibman, J, Electrocardiography in Infants and
Children, pp 79-98. New York, Grune and Stratton, 1966.

\section{"Press that bruise"}

SIR,-Surely the argument used by $\mathrm{Dr}$ Michael Bennett (23 October, p 1010) is fallacious. The application of pressure in controlling haemorrhage is related to but not dependent on the bleeding time. When the test is performed no pressure is applied to the wound site, and the time of the spontaneous cessation of bleeding recorded.

Using Dr Bennett's logic, pressure in excess of $7 \mathrm{~min}$ should be applied to the site of every venepuncture. $\mathrm{Mr}$ B M Tracey (2 October, p 814) is right to "press that bruise" for 3-5 $\min$.

Treloar Haemophilia Centre,

Lord Mayor Treloar Hospital,

Lord Mayor

\section{Hyposensitisation with house dust} mite vaccine in bronchial asthma

SIR,-In commenting on our article (4 September, p 561) Drs J O Warner and J F Price (16 October, p 945) point out that trials of treatment in bronchial asthma are difficult because of the heterogeneity and intermittent nature of the disease, a point of which we are well aware. Only patients who satisfied the accepted criteria for the diagnosis of asthma ${ }^{1}$ were included in the trial, and all the patients had a rise in the forced expiratory volume in $1 \mathrm{~s}\left(\mathrm{FEV}_{1}\right)$ of at least $15 \% 14 \mathrm{~min}$ after the inhalation of an aerosol bronchodilator, so that they ali had bronchial lability. Their sensitivity to the house dust mite was based on criteria used by other authors-namely, a positive prick test reaction to Dermatophagoides pteronyssinus and also either an unequivocal history of symptoms being provoked by contact with household dust or a positive reaction to nasal challenge with $D$ pteronyssinus. ${ }^{2}$ This latter test has been found to provoke positive reactions in $86 \%$ of house dust mite sensitive subjects, as does bronchial challenge in the same proportion, but nasal challenge does not lead to attacks of asthma and is therefore safer. ${ }^{3}$

Before treatment total and specific $D$ pteronyssinus serum IgE levels were measured, but the range was wide and this test was not helpful in identifying those who might benefit from therapy. We have found the FEV $\mathrm{V}_{1}$ to be as good an indicator of changes in bronchial calibre following a bronchodilator in patients with airways obstruction as the specific conductance (SGaw) measured in a body plethysmograph. ${ }^{4}$ Moreover, changes in the $\mathrm{FEV}_{1}$ probably reflect changes in both small and large airways better than SGaw which is more affected by changes in the larger airways. ${ }^{5}$ 